\title{
ERRATUM
}

\section{Effect of Caffeine on Ceftriaxone Disposition and Plasma Protein Binding in the Rat}

\author{
Kwang I. Kwon' ${ }^{1}$ and David W. A. Bourne ${ }^{2,3}$
}

The corrected equation which should have appeared on p. $400^{4}$ follows:

$$
\frac{d C u}{d C}=\frac{1}{2}+\frac{K C-K P_{t}+1}{2\left[\left(K C-1-K P_{t}\right)^{2}+4 K C\right]^{1 / 2}}
$$

and

$$
\begin{aligned}
\frac{d C}{d t}= & K_{\mathrm{KP}} C_{\mathrm{kidney}}+K_{\mathrm{LP}} C_{\text {liver }}+K_{\mathrm{GP}} C_{\mathrm{gut}}+K_{\mathrm{HP}} C_{\text {beart }}+K_{\mathrm{LuP}} C_{\text {lung }} \\
& +K_{\mathrm{BP}} C_{\text {brain }}+K_{\mathrm{MP}} C_{\text {muscle }}+K_{\mathrm{EP}} C_{\mathrm{etc}} \\
& -\left(K_{\mathrm{PK}}+K_{\mathrm{PL}}+K_{\mathrm{PG}}+K_{\mathrm{PH}}+K_{\mathrm{Plu}}+K_{\mathrm{PB}}+K_{\mathrm{PM}}+K_{\mathrm{PE}}\right) C_{\text {plasma }}
\end{aligned}
$$

\footnotetext{
${ }^{1}$ Department of Pharmacy, University of Queensland, St. Lucia, Q 4067, Australia.

${ }^{2}$ Present address: College of Pharmacy, University of Oklahoma, Oklahoma City, Oklahoma 73190.

${ }^{3}$ To whom correspondence should be addressed.

${ }^{4}$ J. Pharmacokin. Biopharm. 14:397-408 (1986).
} 